\title{
Bifurcation and Chaos in Converter Interfaces in Solar PV Systems-A Review
}

\author{
M. Subashini* and M. Ramaswamy
}

Department of Electrical Engineering, Annamalai University, Annamalai Nagar 608002, India

Received 25 April 2017; Accepted 20 September 2017

\begin{abstract}
The paper attempts to present a detailed study of the nonlinear phenomena that includes bifurcations, sub-harmonics and chaos in an effort to arrive at the appropriate choice of converter interface suitable for specific PV systems and evolve criterions for their design and control. The resurgence of switching dc-dc converters as power processing units in renewable energy applications appear to open up new perceptions for harnessing energy efficiency. The focus orients to review the modelling techniques used for nonlinear analysis in the different operating modes of the converter and identify the gap in the related domain with special relevance to the converter interfaces in solar PV systems. The exercise incites to explain the forms of bifurcations, the routes to chaos and the associated control techniques for arbitrating its significance in this perspective. The benefits of analysis of nonlinear phenomena in regulatory applications claim a new space in energy processing applications and forge to explore their role as maximum power point (MPP) trackers. The emphasis endeavours to enhance the scope of use of solar energy and offer a fresh dimension to support the clean energy act and perpetuate the desire to enliven a greener world.
\end{abstract}

Keywords: Bifurcations, Chaos, Sub-harmonics, Nonlinearity, DC-DC converter, Solar PV

\section{Introduction}

The global energy- induced $\mathrm{CO}_{2}$ emissions continue to increase from around 35.6 billion metric tons in 2020 to 43.2 billion metric tons in 2040 [1]. The challenge envisages higher penetrations of renewable energy in an effort to preserve the ecosystems and gather a biodiversity with higher environmental and socio-economic benefits in the process of transitioning to a Green Economy [2]. The path foresees a co-ordinated growth of renewable energy and augurs the demands of the national economy through effective industrial restructuring and formulation or adaption of appropriate policies [3].

The nation appears to experience a massive growth especially in solar energy capacity from $5 \mathrm{GW}$ in 2006 to $5.167 \mathrm{GW}$ in 2015[4]. The solar policy initiatives that include accelerated depreciation, generation based incentives, tax holidays, net metering, diverse feed-in tariffs and emphasis on manufacturing and $R \& D$ in solar PV components forge to perpetuate the generation of solar PV [5]. The technological up gradation in PV industry augurs a fresh perspective to comply the commercial availability of the solar distributed power generation for a sustainable market growth [6].

The lower conversion efficiency of PV remains as a main barrier against successful implementation of the solar projects. The commercialized silicon solar cells offer an average efficiency ranging from $14 \%$ to $17 \%$. However solar energy can be directly converted into direct current (dc) electricity through photovoltaic (PV) array, in which case it becomes important to match the array voltage corresponding

*E-mail address: subashini.2008@gmail.com

ISSN: 1791-2377 @ 2017 Eastern Macedonia and Thrace Institute of Technology. All rights reserved. doi:10.25103/jestr.105.11 to the maximum dc power produced by PV panels to that of the load under real-world operating conditions [7-8].

The switching power converters that form part of an integral solar PV system turn out to be the prime source of nonlinearity, nonlinear components such as diodes and feedback controls adds to the richness of nonlinearity. It assumes significance to investigate the nonlinear phenomena including bifurcations, coexisting attractors and chaos in order to design reliable power electronic interfaces [9].

The maximum power point tracker (MPPT) relies on moving the operating PV voltage or current to extract the maximum power. The tracker usually requires a high efficiency power processing circuits called dc-dc converter to sweep the PV power [10]. The type of converter and its parameters sizing significantly affects the optimum operation of the PV systems. A judicious choice of the converter in accordance with the requirements of the load allows the MPPT to extract the maximum converter efficiency [11].

The current-voltage (I-V) properties of PV array exhibit a nonlinear characteristic that varies under environmental conditions create a phenomenon called chaos. It incites to be a field of emerging cross-disciplinary science of nonlinear dynamics that inherit to be highly sensitive to initial conditions [12]. A large variety of strange behaviours emanate in nonlinear systems such as sub-harmonics, quasiperiodic oscillation, intermittency, and apparently random motion [13].

Besides the converter composes of a set of reactive components and switching devices sandwiched to deliver the energy proficiently from the source to the load when driven, controlled and modulated by appropriate techniques. It brings in nonlinear behaviours and on its part serve to introduce chaos. Chaos research opens up the possibility of the application of nonlinear characteristics in power 
electronic systems and might require fresh approaches to improve the performance of the solar PV systems [14].

Thus the different dynamic behaviours exhibited both by the PV array and the switching power converter invites a detailed study of the available stability models to predict the boundary between such dynamic behaviours. The entire system might exhibit what relates to as bifurcation phenomena under some supply and load conditions. The suppression of chaos and sub harmonic oscillations for a wide range of input voltage and loads thus form to be a prime design constraint in the PV system control.

\section{Modelling Techniques for Nonlinear Analysis of DC- DC Converter}

The two major traditional approaches to model the switching dc-dc converters rely on small signal analysis based on linearization and state space averaging using PWM switch model. The inability to predict the fast scale dynamics by conventional approaches follows it up with sampled data modelling technique which become naturally suitable for power converters owing to its recurrent way operation and control [15].

The stacked solution to each of the state equation for each circuit configuration over one switching cycle provides a large signal discrete-time nonlinear difference equation showing the total increment acquired during a cycle. The approximation by piecewise linear segments gives an approximated large signal discrete time model with reduced complexity in analysing the nonlinear behaviour while retaining the fundamental nonlinear properties of the system [16].

The discrete-time maps find use in the boost converters to represent the assignation rule, which assigns the actual state vector (inductor current and capacitor voltage) to the next state [17]. The derivation of an iterative map with the general form $\mathrm{x}_{\mathrm{n}+1}=\mathrm{f}\left(\mathrm{x}_{\mathrm{n}}\right)$ produces maps with dimensions higher or equal than two which makes the analysis difficult.

The output voltage essentially remains constant due to the presence of the capacitor in the buck converter particularly with sufficiently smaller clock periods compared to the time constant. The system reduces to the 1-D form and the inductor current waveform becomes piecewise linear, allowing simplicity in modelling [18].

A new sampled-data model for the current-mode controlled buck converter including the effects of delay in the pulse-width-modulator (PWM) determines the correct method of measuring the current loop gain [19]. The poincare map obtained by sampling the system trajectory at the rate of switching frequency enables to study the stability of the dual channel resonant buck converter systems by analysing the local behaviour of the map near periodic state denoted by a fixed point in it [20].

The Filippov's method of differential inclusions, in the absence of a nonlinear map obtains the linearization around a periodic orbit for a voltage-mode-controlled buck converter. A monodromy matrix composed of the state transition matrices for the pieces of the orbit that lie in the individual subsystems and the saltation matrix that connects the perturbation just before a switching to that just after [21].

The literature reports the exhaustive scope of the Fourier series expansion of the steady-state feedback signal, time domain analysis of steady-state feedback signal and the introduction of auxiliary state vector for the process of modelling the converters [22-24]. A summary of contributions of modelling techniques of the nonlinearities in various DC-DC converter with remarkable elucidation of consequences in the study of stability of such systems are reported in Tab.1.

Table 1. Modelling techniques for nonlinear analysis of DC-DC converters

\begin{tabular}{|c|c|c|c|c|}
\hline S. No. & $\begin{array}{l}\text { Ref. } \\
\text { No. }\end{array}$ & $\begin{array}{l}\text { Converter } \\
\text { analysed }\end{array}$ & $\begin{array}{l}\text { Modelling } \\
\text { technique }\end{array}$ & Remarks \\
\hline 1 & 15 & $\begin{array}{l}\text { Voltage fed series } \\
\text { resonant converter }\end{array}$ & $\begin{array}{l}\text { Sampled data } \\
\text { dynamic model }\end{array}$ & $\begin{array}{l}\text { Described both large signal dynamics and the dynamics of small } \\
\text { perturbations about cyclic steady state operation. } \\
\text { Model used to design state feedback and periodic output } \\
\text { feedback control system for the converter }\end{array}$ \\
\hline 2 & 16 & $\begin{array}{l}\text { Voltage mode } \\
\text { PWM buck } \\
\text { converter }\end{array}$ & $\begin{array}{l}\text { Iterated } \\
\text { nonlinear } \\
\text { mappings }\end{array}$ & $\begin{array}{l}\text { Predicted the behaviour of real converters such as multiple } \\
\text { pulsing, skipped cycles, sub-harmonics and chaos outside the } \\
\text { province of conventional linearized modelling. } \\
\text { Involved complexity like tedious analytical derivation and } \\
\text { numerical computation }\end{array}$ \\
\hline 3 & 17 & $\begin{array}{l}\text { Current controlled } \\
\text { SEPIC and boost } \\
\text { converter in CCM }\end{array}$ & $\begin{array}{l}\text { Discrete time } \\
\text { model built by } \\
\text { stroboscopic } \\
\text { mapping }\end{array}$ & $\begin{array}{l}\text { stroboscopic map obtained by uniform } \\
\text { sampling of the system state at the switching frequency. } \\
\text { Model used to investigate the nonlinearities of converter through } \\
\text { characteristic multipliers and computation of Lyapunov exponent }\end{array}$ \\
\hline 4 & 18 & $\begin{array}{l}\text { Current controlled } \\
\text { buck converter }\end{array}$ & $\begin{array}{l}\text { One dimensional } \\
\text { mapping }\end{array}$ & $\begin{array}{l}\text { Model developed for ideal switching, missed switching caused } \\
\text { by delay and missed switching caused by switching transient. } \\
\text { Changes seen in bifurcation diagram developed from model of } \\
\text { ideal conditions and model with switching delay and transients. }\end{array}$ \\
\hline 5 & 19 & $\begin{array}{l}\text { Peak Current } \\
\text { controlled Boost } \\
\text { converter }\end{array}$ & $\begin{array}{l}\text { One dimensional } \\
\text { discrete time } \\
\text { map }\end{array}$ & $\begin{array}{l}\text { Model obtained from inductor current waveform and the solution } \\
\text { of ODE describing boost converter with duty cycle as state } \\
\text { variable. } \\
\text { Model allowed for studying the nonlinearity of converter with } \\
\text { any of its parameter as a bifurcation parameter. } \\
\text { Model used to confirm period doubling, intermittency and } \\
\text { chaotic behaviour. }\end{array}$ \\
\hline 6 & 20 & $\begin{array}{l}\text { Dual channel } \\
\text { resonant buck } \\
\text { converter in }\end{array}$ & $\begin{array}{l}\text { Poincare map } \\
\text { function }\end{array}$ & $\begin{array}{l}\text { Model used to test the stability of voltage feedback control loop } \\
\text { by the Eigenvalues of Jacobian matrix of the Poincare map. } \\
\text { Model identified Hopf bifurcation with a large increase in } \\
91\end{array}$ \\
\hline
\end{tabular}




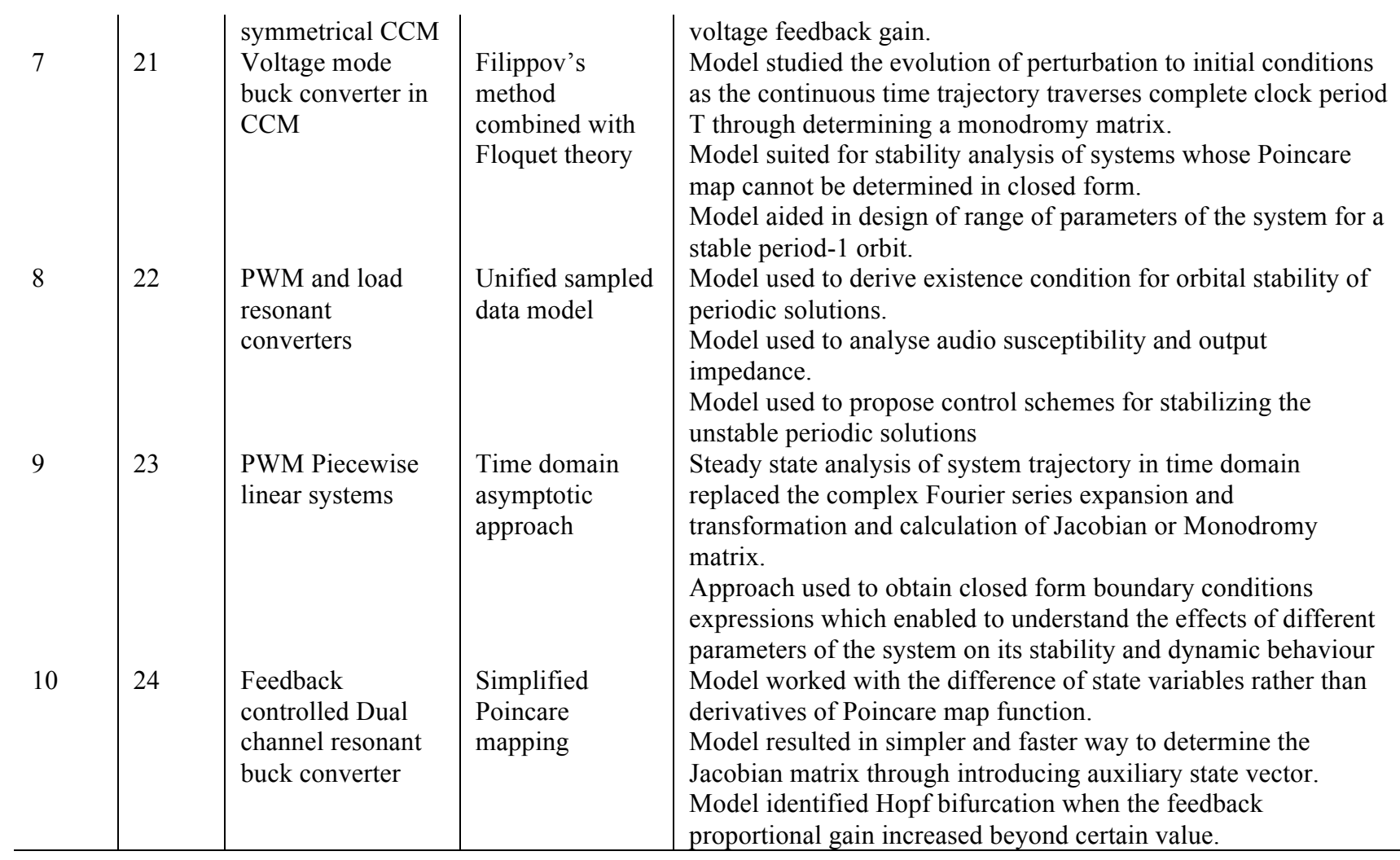

\section{Types of Bifurcations in DC-DC Converters}

The bifurcation diagram constitutes to be a powerful tool to investigate the nonlinear phenomena, where in the periodic steady state of the system exists either as a signal point or several points equal to the periodicity of the system for a fixed parameter. It necessitates plotting numerous points in the diagram because chaos means period infinity and ensures that the points do not fall at the same position. [25].

The saddle node bifurcation shown in Fig.1 occurs at a critical parameter value where on one side of it, there occurs multiple solutions (attractors) and on the other side of it, no solution exists. With the voltage loop closed and a large feedback gain in the voltage loop, the converter does not result in saddle node as in Fig.1 [26]. It derives the critical conditions of bifurcations of the valley current mode control in the boost converter at light loading [27]. The saddle node bifurcation occurs in the boost converter if it exercises a control of the output voltage. However it does not occur if the system does not consider the parasitic inductor resistance [28].



Fig. 2. Occurrence of Hopf bifurcation through torus breakdown as in [29]

A fourth-order current-controlled Cuk converter operates chaotically even in free-running (autonomous) mode and the computer simulations of the circuits reveal the bifurcation from the stable equilibrium state (fixed point), through limit

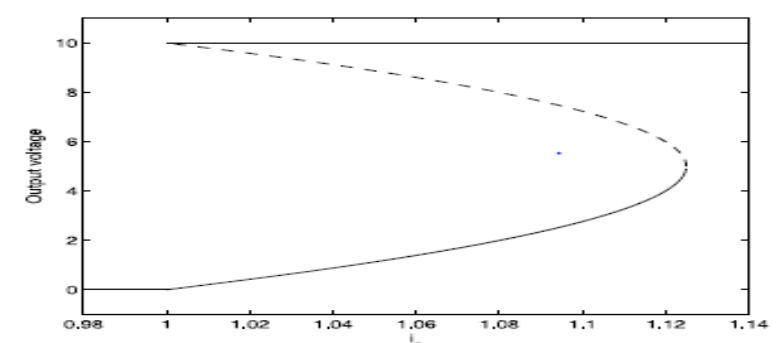

Fig. 1. Occurrence of Saddle node bifurcation for converter operation as in [26]

A stable periodic orbit may bifurcate to a stable torus at a certain point of the parameter space as in Fig. 2. It refers to a kind of bifurcation is called the Neimarck-Sacker bifurcation, or the Hopf bifurcation of the associated discrete-time dynamics and occurs on the period of the free oscillations of the RLC circuit (the natural period) being larger than the pulse width modulation (PWM) period. The behaviour of a closed loop boost converter, with a variation of the PWM period exhibits that Hopf bifurcation occurs at a certain value of the parameters [29].

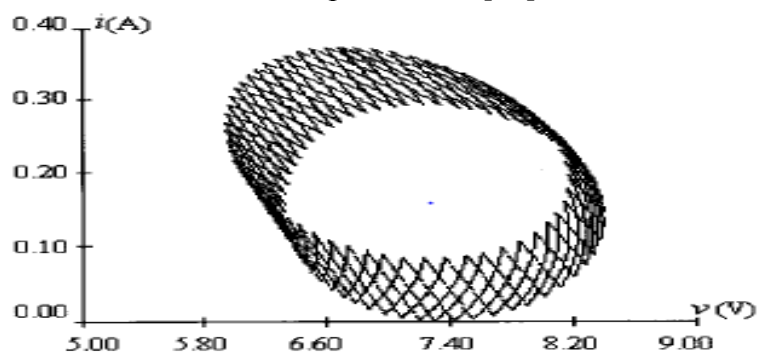

cycles and quasi-periodic orbits, and eventually to chaos [30].

A continuous time model explains the bifurcations in current controlled Luo topology operating in the continuous conduction mode. The dynamics obtained by varying the 
load and reference voltage, with the remaining parameters constant show a fundamental operation initially and eventually to enter into the chaotic regime through a quasi periodic operation [31].

A condition for period doubling bifurcation expressed in terms of the solvability of a pair of algebraic equations requires the design of a feed forward control scheme used to adjust the compensating ramp and stabilizing the buck converter [32].The evolution process of period-doubling bifurcation from period-1 to period-2, then to period-4 appears in a voltage mode controlled fly-back converter operating in discontinuous conduction mode (DCM) with feedback gain $\mathrm{k}$ as bifurcation parameter [33].

The averaged model of a boost converter functioning in the continuous current mode (CCM) with slope compensation as bifurcation parameter allows estimating the period-doubling bifurcation point and the diagram as seen from Fig.3. The corresponding values of the slope compensation at the loss of the asymptotic stability of the proposed average model leading to creation of a $2 \mathrm{~T}$ periodic orbit turns out to be consistent with those at the onset of the first period-doubling bifurcation obtained by simulations [34].

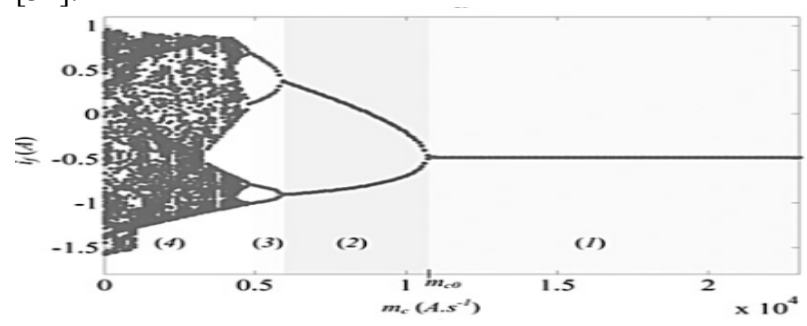

Fig. 3. Occurrence of period doubling bifurcation as in [34]

The Table 2 summarizes the types of bifurcations seen in various dc-dc converter and their operation and control insights.

Table 2. Bifurcation types observed in DC-DC converter operation

\begin{tabular}{|c|c|c|c|c|}
\hline $\begin{array}{l}\text { S. } \\
\text { No. }\end{array}$ & $\begin{array}{l}\text { Ref. } \\
\text { No. }\end{array}$ & $\begin{array}{l}\text { Converter and } \\
\text { operation mode }\end{array}$ & $\begin{array}{l}\text { Type of } \\
\text { bifurcation }\end{array}$ & Bifurcation parameters and remarks \\
\hline 1 & 25 & $\begin{array}{l}\text { Current } \\
\text { controlled Buck- } \\
\text { boost converter }\end{array}$ & Period doubling & $\begin{array}{l}\text { Output voltage studied with input voltage, reference current and } \\
\text { load resistance as bifurcation parameter. } \\
\text { PDB occurred with decrease in input voltage and increase in } \\
\text { reference current and load resistance. }\end{array}$ \\
\hline 2 & 26 & $\begin{array}{l}\text { Buck converter } \\
\text { with constant } \\
\text { current load }\end{array}$ & $\begin{array}{l}\text { Saddle node } \\
\text { (SNB) and period } \\
\text { doubling (PDB) }\end{array}$ & $\begin{array}{l}\text { Output voltage studied with current control signal as bifurcation } \\
\text { parameter. } \\
\text { For pure CCL SNB occurred at } D=1 / 2 \text {. For CCL parallel with } \\
\text { resistive load SNB occurred at light loading. For VMC or CMC } \\
\text { with voltage loop closed SNB did not occurred. }\end{array}$ \\
\hline 3 & 27 & $\begin{array}{l}\text { Peak and valley } \\
\text { current } \\
\text { controlled boost } \\
\text { converter with } \\
\text { light loading }\end{array}$ & $\begin{array}{l}\text { Border collision } \\
\text { (BCB), Saddle } \\
\text { node (SNB) and } \\
\text { period doubling } \\
\text { (PDB) }\end{array}$ & $\begin{array}{l}\text { Dimensionless parameter } \mathrm{K}=2 \mathrm{~L} / \mathrm{RT}<1 \text { related to light loading } \\
\text { studied with scaled steady state valley current } \mathrm{I}_{\mathrm{c}}=2 \mathrm{~L} / \mathrm{V}_{\mathrm{s}} \mathrm{T} \text { as } \\
\text { bifurcation parameter }\end{array}$ \\
\hline 4 & 28 & $\begin{array}{l}\text { Buck and Boost } \\
\text { converter in } \\
\text { Current mode } \\
\text { control and } \\
\text { voltage mode } \\
\text { control }\end{array}$ & $\begin{array}{l}\text { Saddle node and } \\
\text { Neimark or period } \\
\text { doubling } \\
\text { Bifurcation }\end{array}$ & $\begin{array}{l}\text { Buck converter output voltage studied with Peak inductor current } \\
\text { control signal as bifurcation parameter } \\
\text { Boost converter duty cycle studied with reference voltage as } \\
\text { bifurcation parameter }\end{array}$ \\
\hline 5 & 29 & $\begin{array}{l}\text { PWM voltage } \\
\text { controlled boost } \\
\text { converter }\end{array}$ & Hopf Bifurcation & $\begin{array}{l}\text { Output voltage studied with period of the PWM as bifurcation } \\
\text { parameter }\end{array}$ \\
\hline 6 & 30 & $\begin{array}{l}\text { Autonomous free } \\
\text { running Cuk } \\
\text { converter }\end{array}$ & Hopf Bifurcation & $\begin{array}{l}\text { System state trajectories studied through phase portraits with a } \\
\text { dimensionless parameter } \mathrm{K}=\mathrm{i}_{1}+\mathrm{i}_{2}+\mu \mathrm{V}_{1} \text { as bifurcation parameter }\end{array}$ \\
\hline 7 & 31 & $\begin{array}{l}\text { Current } \\
\text { controlled Luo } \\
\text { converter in } \\
\text { CCM }\end{array}$ & Hopf Bifurcation & $\begin{array}{l}\text { Inductor current studied with load and reference voltage as } \\
\text { bifurcation parameter }\end{array}$ \\
\hline 8 & 32 & $\begin{array}{l}\text { Voltage } \\
\text { controlled buck } \\
\text { converter }\end{array}$ & $\begin{array}{l}\text { Period doubling } \\
\text { bifurcation }\end{array}$ & Output voltage studied with input voltage as bifurcation parameter \\
\hline 9 & 33 & $\begin{array}{l}\text { Voltage } \\
\text { controlled } \\
\text { flyback } \\
\text { converter in } \\
\text { DCM }\end{array}$ & $\begin{array}{l}\text { Period doubling } \\
\text { bifurcation }\end{array}$ & $\begin{array}{l}\text { Output voltage studied with feedback voltage gain as bifurcation } \\
\text { parameter }\end{array}$ \\
\hline 10 & 34 & $\begin{array}{l}\text { CCM boost } \\
\text { converter and } \\
\text { DC active filter } \\
\text { converter }\end{array}$ & $\begin{array}{l}\text { Period doubling } \\
\text { bifurcation }\end{array}$ & $\begin{array}{l}\text { Inductor current and Output voltage studied with slope of } \\
\text { compensating ramp as bifurcation parameter }\end{array}$ \\
\hline
\end{tabular}




\section{Study of Mechanism of Bifurcations and Transition to Chaos}

The study of mechanism relating to the loss of stability of period-1 orbit and transition to chaos may provide sufficient understanding in the design of converters that are reliable and predictable in their performance when operating in unstable modes or even chaotically. It can also help in designing control methods for sustaining the stability of the systems. The thoughtfulness of the routes to chaos in converter systems allows engineering the systems with a higher degree of confidence as stable systems through quasi periodic route to chaos, period doubling route chaos and intermittency route to chaos.

The investigations reveal the quasi periodic route to chaos in boost, buck-boost and load resonant converters under various operating conditions 35] - [37] and Fig.4.illustrates that of a boost converter. The dynamics of output voltage of boost converter exhibited period doubling route to chaos by increasing the feedback control gain of proportional controller in [38]. The numerical and experimental results of period doubling route to chaos in voltage controlled buck converter in CCM with input voltage as bifurcation parameter reported in [39] illustrated through phase portraits in Fig.5. [40] show the period doubling route to chaos through period-1,2,4 and 8 and finally exhibits the chaotic attractor.

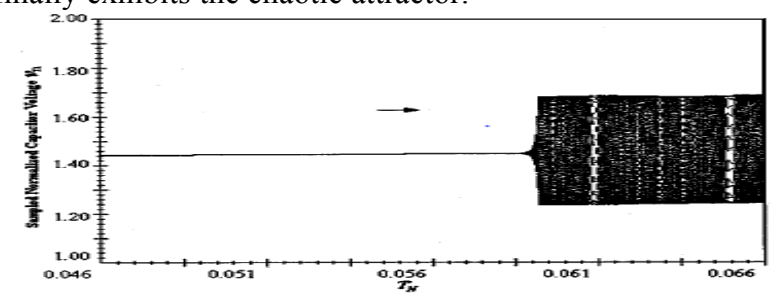

Fig. 4. Illustration of Quasi-periodic route to chaos as in [36]
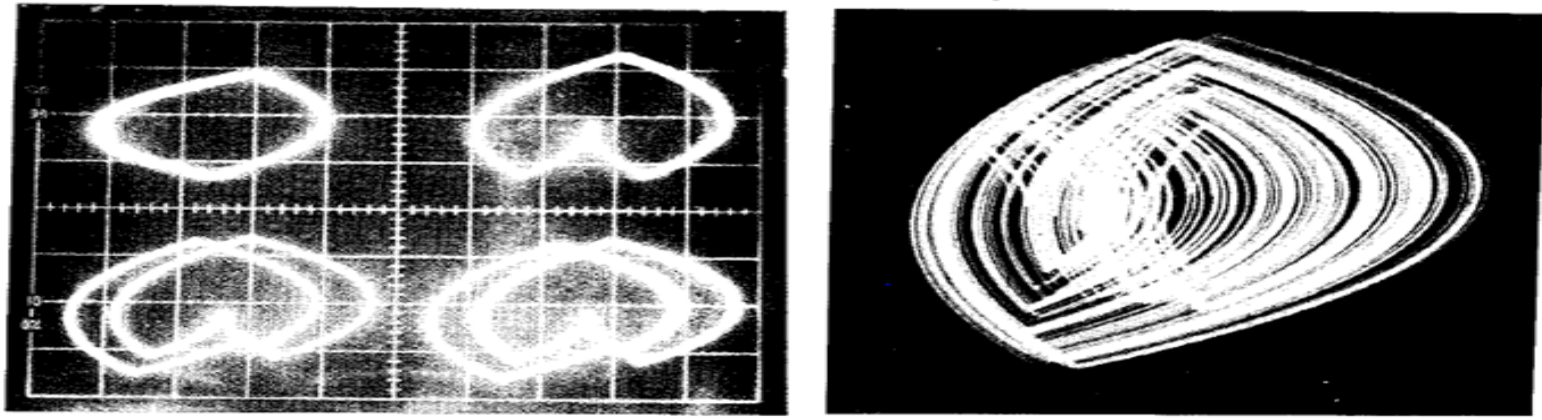

Fig. 5. Experimental Illustration of period doubling route to chaos as in [39]

The intermittency route to chaos occurs in switching power supplies, not protected against the intrusion of spurious signals or in the presence of parasitic inductances and capacitances [41]-[43] for single and interleaved buck converter with the addition of the intrusion of interference into the input and reference voltages. The Fig. 6 exhibits the intermittency route to chaos as the strength of the intrusion signal increases in the inductor current waveform.

\section{Control of Chaos}

The idea of control over chaos represents a fundamental break from the previous approaches since, while the system remains in a chaotic state, it stabilizes on one of the unstable periodic orbits. Through small perturbations, the unpredictable (undesirable) dynamics transforms into
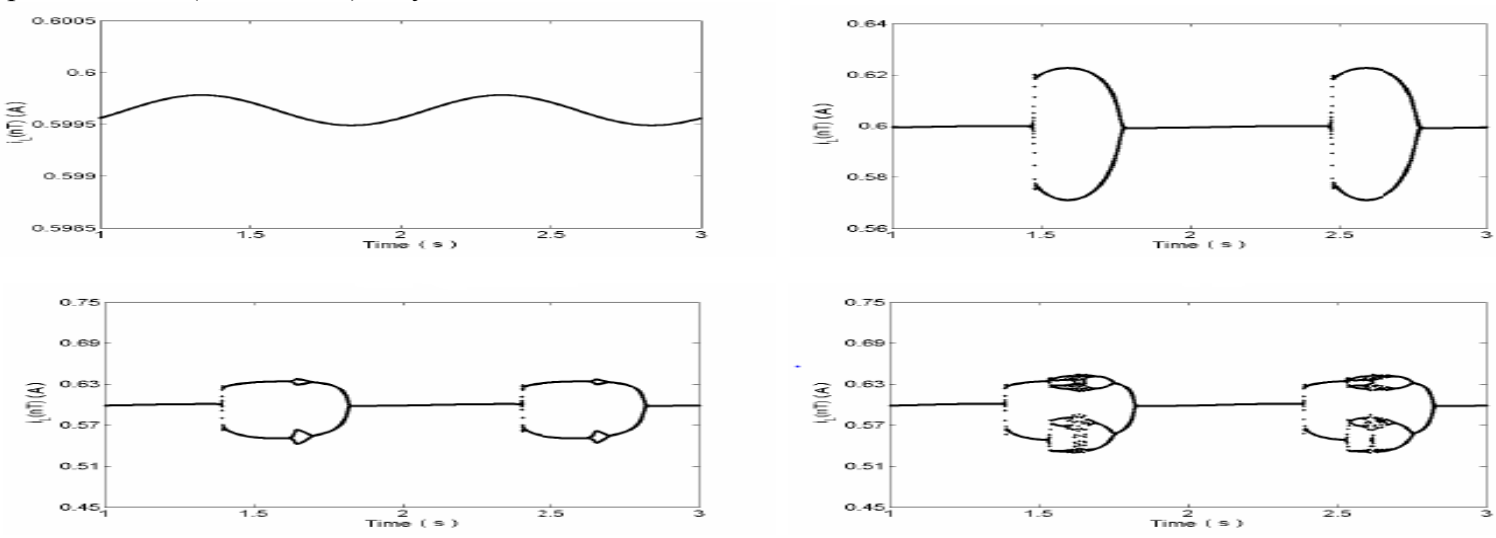

Fig. 6. Simulated illustration of intermittency route to chaos through inductor current waveforms as in [42]

predictable (desirable) behaviour without major changes to the functioning conditions [44].

A host of control methods to control chaos in various dcdc converters namely OGY method, Nonlinear time delayed feedback controller, Control of triangular wave used in PWM, sliding mode control, resonant parametric perturbation, adaptive ramp technique and washout filter find spread use [45]-[50]. The phenomenon of bifurcation, sub-harmonics and chaos emanates in dc-dc converters used in energy applications employing PV panels [51]-[54]. The criteria of occurrence of such nonlinearities and its consequences on the performance of the overall PV system operation urge attention and the methods to govern the incidence of nonlinearity and control its effects on system process with a vision of achieving desired energy efficiency poses challenges.






\section{Control of Chaos}

The idea of control over chaos represents a fundamental break from the previous approaches since, while the system remains in a chaotic state, it stabilizes on one of the unstable periodic orbits. Through small perturbations, the unpredictable (undesirable) dynamics transforms into predictable (desirable) behaviour without major changes to the functioning conditions [44].

A host of control methods to control chaos in various dcdc converters namely OGY method, Nonlinear time delayed feedback controller, Control of triangular wave used in PWM, sliding mode control, resonant parametric perturbation, adaptive ramp technique and washout filter find spread use [45]-[50]. The phenomenon of bifurcation, sub-harmonics and chaos emanates in dc-dc converters used in energy applications employing PV panels [51]-[54]. The criteria of occurrence of such nonlinearities and its consequences on the performance of the overall PV system operation urge attention and the methods to govern the incidence of nonlinearity and control its effects on system process with a vision of achieving desired energy efficiency poses challenges.

\section{Criteria for Topology Selection for PV System}

The topology study in [55] reports that the boost converter to be advantageous in PV MPPT applications compared to buck converters in terms of continuous input current, dynamic response and cost. It allows elimination of high side driver for the switch and additional blocking diode as advantages of boost converter over the buck counterpart. The buck-boost converters offer to be a suitable topology so as to provide perfect MPPT since there exists no dependencies on loading or environmental conditions. In spite of its voltage flexibility the buck-boost converter turns out to be always efficiency, or price disadvantaged [56] and [57].

In order to increase the voltage flexibility, the scenario of selection of converter topologies experience a transition to cuk, SEPIC and Luo converters, suitable for standalone systems. The cuk converter shows an inverted output and comparatively higher diode power loss than the SEPIC. The SEPIC converter exhibits better dynamics of MPPT and found more stable at MPP than Cuk converter. A significant step up in the voltage required as in $340-\mathrm{V}$ minimum dc bus voltage for $240-\mathrm{V}$ transformer-less ac grid connection can be achieved by positive output super-lift Luo converter which operates in first quadrant with large voltage amplification and high voltage transfer gain. It enjoys a higher power density and efficiency at higher power ratings [58] - [60].

\section{Conclusion}

The dc-dc converters have been designed conventionally to work under a constant voltage source and therefore their behaviours deem not to comply the desired requirements when connected to a variable current source like a photovoltaic panel. The operating conditions of dc-dc converters in such applications has been seen to be widely different than in the aforementioned studies and hence demands a great need for further research. The boost converter has been on focus for low rated PV MPPT applications and demands perception of nonlinear analysis and control of chaos to efficiently transfer the available power from panel to load.

The SEPIC converter has been slated for such medium rated PV with battery charging applications and augurs a study for nonlinearities and its control in various modes. The positive-output super-lift Luo, owing to its high efficiency and low switching loss has been seen to suit high power industrial applications where large voltage boost becomes a necessity from the available low-voltage sources. The survey has been forayed to suggest that boost, SEPIC and positive output super-lift Luo converter as potential topologies to be used in solar PV MPPT applications. The detailed analysis of their dynamical behaviour and its influence on the overall PV system performance will provide useful guidelines for choice and design of converters and deeper insights in devising control strategies for various modes that will ensure the reliability and predictability of the complete system.

\section{Acknowledgment}

The authors thank the authorities of Annamalai University for providing the necessary facilities to accomplish this piece of work.

Access article distributed under the terms of the Creative Commons Attribution Licence

\section{References}

[1] https://www.eia.gov/forecasts/ieo/emissions.cfm

[2] A. Gasparatos, C. N. H. Doll, M. Esteban, A. Ahmed, and T. A. Olang, "Renewable energy and biodiversity: Implications for transitioning to a Green Economy," Renewable and Sustainable Energy Reviews, vol. 70, pp. 161-184, Apr. 2017

[3] Y. Xiao, X. Wang, X. Wang, Z. Wu, and W. Liu, "The Coordinated Development Path of Renewable Energy and National Economy in China Considering Risks of Electricity Market and Energy Policy," IEEE Transactions on Industrial Informatics, pp. 1-1, 2017

[4] http://www.irena.org/DocumentDownloads/Publications/IRENA_RE Capacity Statistics 2016.pdf

[5] O. V. Bapat and V. N. Bapat, "An overview of solar energy policy of India and few prominent nations in the world," 2016 IEEE 1st International Conference on Power Electronics, Intelligent Control and Energy Systems (ICPEICES), Jul. 2016

[6] S. Manju and N. Sagar, "Progressing towards the development of sustainable energy: A critical review on the current status, applications, developmental barriers and prospects of solar photovoltaic systems in India," Renewable and Sustainable Energy Reviews, vol. 70, pp. 298-313, Apr. 2017

[7] M. K. Hairat and S. Ghosh, "100 GW solar power in India by 2022 - A critical review," Renewable and Sustainable Energy Reviews, vol. 73, pp. 1041-1050, Jun. 2017

[8] J.-A. Jiang, Y.-L. Su, K.-C. Kuo, C.-H. Wang, M.-S. Liao, J.-C. Wang, C.-K. Huang, C.-Y. Chou, C.-H. Lee, and J.-C. Shieh, "On a hybrid MPPT control scheme to improve energy harvesting performance of traditional two-stage inverters used in photovoltaic systems," Renewable and Sustainable Energy Reviews, vol. 69, pp. 1113-1128, Mar. 2017

[9] Soumitro Banerjee, and George C. Verghese, "Nonlinear phenomenon in power electronics Attractors, bifurcations chaos and nonlinear control," Wiley-IEEE Press, July 2001.

[10] N. Karami, N. Moubayed, and R. Outbib, "General review and classification of different MPPT Techniques," Renewable and Sustainable Energy Reviews, vol. 68, pp. 1-18, Feb. 2017 
[11]S. Kolsi, H. Samet, and M. B. Amar, "Design Analysis of DC-DC Converters Connected to a Photovoltaic Generator and Controlled by MPPT for Optimal Energy Transfer throughout a Clear Day," Journal of Power and Energy Engineering, vol. 02, no. 01, pp. 2734, 2014.

[12]. https://en.wikipedia.org/wiki/Chaos theory

[13]W. Yuanbin, "Research on Chaos in Switching Dc-Dc Converters," 2009 Second International Conference on Intelligent Computation Technology and Automation, 2009.

[14] B. Zhang and X. Wang, "Chaos Analysis and Chaotic EMI Suppression of DC-DC Converters," Sep. 2014.

[15] M. E. Elbuluk, G. C. Verghese, and J. G. Kassakian, "Sampleddata modeling and digital control of resonant converters," IEEE Transactions on Power Electronics, vol. 3, no. 3, pp. 344-354, Jul. 1988.

[16] D. C. Hamill, J. H. B. Deane, and D. J. Jefferies, "Modeling of chaotic DC-DC converters by iterated nonlinear mappings," IEEE Transactions on Power Electronics, vol. 7, no. 1, pp. 25-36, 1992.

[17] A. Kavitha and G. Uma, "Bifurcation Analysis of DC-DC Converters using Discrete Time Model," 2008 Joint International Conference on Power System Technology and IEEE Power India Conference, Oct. 2008.

[18] S. Banerjee, S. Parui, and A. Gupta, "Dynamical Effects of Missed Switching in Current-Mode Controlled dc-dc Converters," IEEE Transactions on Circuits and Systems II: Express Briefs, vol. 51, no. 12 , pp. 649-654, Dec. 2004.

[19] S. C. Yanez-Campos, J. Leyva-Ramos, M. G. Ortiz-Lopez, and R. Femat, "One-dimensional discrete-time map for the analysis of a current controlled boost converter," 2009 IEEE International Conference on Control Applications, Jul. 2009.

[20] O. Dranga and I. Nagy, "Stability analysis of feedback controlled resonant DC-DC converter using Poincare map function," ISIE 2001. 2001 IEEE International Symposium on Industrial Electronics Proceedings (Cat. No.01TH8570).

[21] Stability Analysis of the Continuous-Conduction- Mode Buck Converter Via Filippov's Method

[22] C.-C. Fang, "Sampled-data analysis and control of DC-DC switching converters," Ph.D. dissertation, Dept. Elect. Eng., Univ. Maryland, College Park, 1997

[23] A. El Aroudi, "A Time-Domain Asymptotic Approach to Predict Saddle-Node and Period Doubling Bifurcations in Pulse Width Modulated Piecewise Linear Systems," MATEC Web of Conferences, vol. 16, p. 08004, 2014.

[24] O. Dranga, B. Buti, I. Nagy, and H. Funato, "Stability analysis of nonlinear power electronic systems utilizing periodicity and introducing auxiliary state vector," IEEE Transactions on Circuits and Systems I: Regular Papers, vol. 52, no. 1, pp. 168-178, Jan. 2005.

[25] F. H. Qi and Y. Sun, "Study of Bifurcation and Chaos in the Current-Mode Controlled Boost DC-DC Converter," Applied Mechanics and Materials, vol. 733, pp. 635-638, Feb. 2015

[26] C.-C. Fang, "Saddle-node bifurcation in the buck converter with constant current load," Nonlinear Dynamics, vol. 69, no. 4, pp. 1739-1750, Mar. 2012

[27] C.-C. Fang, "Asymmetric Instability Conditions for Peak and Valley Current Programmed Converters at Light Loading," IEEE Transactions on Circuits and Systems I: Regular Papers, vol. 61, no. 3, pp. 922-929, Mar. 2014.

[28] C.-C. Fang, "Critical conditions of saddle-node bifurcations in switching DC-DC converters," International Journal of Electronics, vol. 100, no. 8, pp. 1147-1174, Aug. 2013.

[29] A. El Aroudi, L. Benadero, E. Toribio, and G. Olivar, "Hopf bifurcation and chaos from torus breakdown in a PWM voltagecontrolled DC-DC boost converter," IEEE Transactions on Circuits and Systems I: Fundamental Theory and Applications, vol. 46, no. 11, pp. 1374-1382, 1999

[30] C. K. Tse, Y. M. Lai, and H. H. C. Iu, "Hopf bifurcation and chaos in a free-running current-controlled Cuk switching regulator," IEEE Transactions on Circuits and Systems I: Fundamental Theory and Applications, vol. 47, no. 4, pp. 448-457, Apr. 2000.

[31] A. Kavitha and G. Uma, "Experimental Verification of Hopf Bifurcation in DC--DC Luo Converter," IEEE Transactions on Power Electronics, vol. 23, no. 6, pp. 2878-2883, Nov. 2008.

[32] W. Li and J. Zhang, "Research of Period Doubling Bifurcation in PWM Buck DC-DC Converter Using Harmonic Balance," 2008 ISECS International Colloquium on Computing, Communication, Control, and Management, 2008.
[33] L.-L. Xie and R.-X. Gong, "Study of the mechanism of perioddoubling bifurcation in DCM flyback converter," 2014 International Power Electronics and Application Conference and Exposition, Nov. 2014

[34] R. Gavagsaz-Ghoachani, J.-P. Martin, B. Davat, B. NahidMobarakeh, S. Pierfederici, and M. Phattanasak, "Generalisation of an averaged model approach to estimate the period-doubling bifurcation onset in power converters," IET Power Electronics, vol. 9, no. 5, pp. 977-988, Apr. 2016.

[35] K. Mandal, S. Banerjee, and C. Chakraborty, "Quasi-periodic route to chaos in load resonant DC-DC converters," 2010 IEEE International Conference on Industrial Technology, 2010

[36] A. El Aroudi and R. Leyva, "Quasi-periodic route to chaos in a PWM voltage-controlled DC-DC boost converter," IEEE Transactions on Circuits and Systems I: Fundamental Theory and Applications, vol. 48, no. 8, pp. 967-978, 2001.

[37] P. Rajarshi and D. Maksimovic, "Analysis of PWM nonlinearity in non-inverting buck-boost power converters," 2008 IEEE Power Electronics Specialists Conference, Jun. 2008

[38] Q. NIU and Z. JU, "Study on Bifurcation and Chaos in Boost Converter Based on Energy Balance Model," Energy and Power Engineering, vol. 01, no. 01, pp. 38-43, 2009.

[39] J. H. B. Deane and D. C. Hamill, "Analysis, simulation and experimental study of chaos in the buck converter," 21st Annual IEEE Conference on Power Electronics Specialists.

[40] W. C. Y. Chan and C. K. Tse, "Studies of routes to chaos for current-programmed DC/DC converters," PESC Record. 27th Annual IEEE Power Electronics Specialists Conference.

[41] C. K. Tse, Yufei Zhou, F. C. M. Lau, and Shui-Sheng Qiu, '“Intermittent' chaos and subharmonics in switching power supplies," Proceedings of the 2003 International Symposium on Circuits and Systems, 2003. ISCAS ' 03.

[42] Z. Li, Y. Zhou, and J. Chen, "Complex Intermittency in VoltageMode Controlled Buck Converter," 2006 5th International Power Electronics and Motion Control Conference, Aug. 2006

[43] P. Deivasundari, K. Murali, G. Uma, and C. Vincent, "Non-linear intermittent instabilities and their control in an interleaved DC/DC converter," IET Power Electronics, vol. 7, no. 5, pp. 1235-1245, May 2014

[44] C. Ivan and A. Serbanescu, "Control methods on unstable periodic orbits of a chaotic dynamical system- control chaos in buck converter," 2008 11th International Conference on Optimization of Electrical and Electronic Equipment, May 2008

[45] Lihong He, Meimei Jia, Zhongwen Dong, and Jianhua Wu, "Chaos control for the Boost converter under current-mode control," 2010 Chinese Control and Decision Conference, May 2010

[46] Somnath Maity, Damian Giaouris, Soumitro Banerjee, Tapas K. Bhattacharya, Bashar Zahawi, and Volker Pickert, "Bifurcation Control of Power Electronic DC-DC Converters," Unpublished

[47] A. Kavitha, G. Indira, and G. Uma, "Analysis and Control of Chaos in SEPIC DC-DC Converter Using Sliding Mode Control," 2008 IEEE Industry Applications Society Annual Meeting, Oct. 2008

[48]A. Kavitha and G. Uma, "Control of chaos by resonant parametric perturbation in a current mode controlled buck-boost Dc-Dc converter," 2008 Twenty-Third Annual IEEE Applied Power Electronics Conference and Exposition, Feb. 2008.

[49] J. D. Morcillo, D. Burbano, and F. Angulo, "Adaptive Ramp Technique for Controlling Chaos and Subharmonic Oscillations in DC-DC Power Converters," IEEE Transactions on Power Electronics, vol. 31, no. 7, pp. 5330-5343, Jul. 2016

[50] W. Ma, M. Wang, and C. Li, "Control of bifurcation in the onecycle controlled Cuk converter," Nonlinear Dynamics, vol. 67, no. 4, pp. 2573-2583, Aug. 2011

[51] P.Deivasundari, G. Uma, and R. Poovizhi, "Analysis and experimental verification of Hopf bifurcation in a solar photovoltaic powered hysteresis current-controlled cascaded-boost converter," IET Power Electronics, vol. 6, no. 4, pp. 763-773 Feb. 2013

[52] Hen-Kung Wang, Po-Lun Chang, Fei-Hu Hsieh,and Hsiang-Yan Hsieh, "Nonlinear Phenomenon in a Current-Mode Controlled Buck-Boost Converter With Solar Cell Input via Varying Reference Current," Proc. Of Int. Conf. on Machine Learning and cybernetics, Jul. 2014.

[53] A. N. Natsheh and J. G. Kettleborough, "Control of chaotic behaviour in buck-boost DC-DC converters," 2012 24th International Conference on Microelectronics (ICM), Dec. 2012

[54] Abdullah Abusorrah, Mohammed M. Al-Hindawi a, Yusuf AlTurki et. al., "Stability of a boost converter fed from photovoltaic source," Sol. Energy, Vol. 98, pp. 458-471. 
[55] Weidong Xiao, Nathan Ozog, and William G. Dunford, "Topology Study of Photovoltaic Interface for Maximum Power Point Tracking," IEEE Trans. On Ind. Electronics, Vol. 54, no. 3, pp. 1696-1704, Jun. 2007

[56]M. E. Başoğlu and B. Çakır, "Comparisons of MPPT performances of isolated and non-isolated DC-DC converters by using a new approach," Renewable and Sustainable Energy Reviews, vol. 60, pp. 1100-1113, Jul. 2016.

[57]M. H. Taghvaee, M. A. M. Radzi, S. M. Moosavain, H. Hizam, and M. Hamiruce Marhaban, "A current and future study on nonisolated DC-DC converters for photovoltaic applications," Renewable and Sustainable Energy Reviews, vol. 17, pp. 216-227, Jan. 2013
[58]S. Sivakumar, M. J. Sathik, P. S. Manoj, and G. Sundararajan, “An assessment on performance of DC-DC converters for renewable energy applications," Renewable and Sustainable Energy Reviews, vol. 58, pp. 1475-1485, May 2016.

[59] James Dunia, and Bakari M. M. Mwinyiwiwa, "Performance Comparison between ĆUK and SEPIC Converters for Maximum Power Point Tracking Using Incremental Conductance Technique in Solar Power Applications," WASET Int. Journal of Elec., Comp., Energetic, Electronic and Communication Engineering Vol:7, No. 12, pp. 1638-1643, 2013.

[60] K. Shalini and J. Barnabas Paul Glady, "Solar Powered Luo Converter for Wiper Motor Application," Indian Journal of Science and Technology, vol. 9, no. 43, Nov. 2016. 